\title{
Resveratrol Limits Lipogenesis and Enhance Mitochondrial Activity in HepG2 Cells
}

Magdalena Izdebska ${ }^{1}$, Mariola Herbet ${ }^{1}$, Monika Gawrońska-Grzywacz ${ }^{1}$, Iwona Piątkowska-Chmiel ${ }^{1}$, Agnieszka Korga ${ }^{2}$, Marcin Sysa ${ }^{1}$, Magdalena Iwan², Dorota Natorska-Chomicka ${ }^{1}$, Ewa Poleszak ${ }^{3}$, Andrzej Wróbel ${ }^{4}$, Sławomir Mandziuk ${ }^{5}$, Jarosław Dudka ${ }^{1}$

${ }^{1}$ Department of Toxicology, ${ }^{2}$ Independent Medical Biology Unit, ${ }^{3}$ Department of Applied Pharmacy, ${ }^{4}$ Second Department of Gynecology and ${ }^{5}$ Department of Pneumology, Oncology and Allergology, Medical University of Lublin, Lublin, Poland.

Received, November 2, 2018; Revised, November 27, 2018; Accepted June 28, 2018; Published, November 29, 2018.

ABSTRACT - Purpose: The aim of this study was to evaluate the effect of resveratrol on de novo lipogenesis in HepG2 cells caused by high glucose concentrations. Increased lipogenesis in the liver is the main reason for the development of nonalcoholic fatty liver disease (NAFLD) - currently one of the most common chronic liver diseases. In developed countries, this disease is mostly associated with nutritional disorders, resulting from the increasing consumption of monosaccharides. Resveratrol is a natural polyphenol with a promising potential for NAFLD treatment. Methods: The steatosis of HepG2 cells was visualized using the intracellular lipid staining by Nile Red dye with a fluorescence microscope. This study also evaluated the effect of resveratrol on the mitochondrial activity (MitoTracker Green staining), dsDNA (Hoechst 33342 staining) and the viability of HepG2 cells treated with high glucose concentrations (25 and $33 \mathrm{mM})$. Results: Current study showed that high glucose concentrations induced fat-overloading in HepG2 cells (microvacuolar steatosis occurred in most of the cells). Resveratrol $(20 \mu \mathrm{M})$ limits the steatosis induction in HepG2 cells by glucose and increased the mitochondrial activity of cells. Resveratrol did not affect the viability of HepG2 cells. Conclusion: This beneficial effect could be helpful in the treatment of NAFLD.

\section{INTRODUCTION}

Lipogenesis is a complex metabolic pathway that synthesizes fatty acids from excess carbohydrates. The deregulation and severity of lipogenesis is often observed in various metabolic diseases such as obesity, non-alcoholic fatty liver disease (NAFLD), type 2 diabetes, metabolic syndrome. In addition, lipogenesis is reported to be elevated in cancer cells and virus infected cells (1).

Nowadays the prevalence of obesity and NAFLD is increasing in developed countries while therapeutic options are limited (2-4). Nutritional disorders such as increased intake of monosaccharides (glucose and/or fructose) are the main causes of these diseases, resulting from increasing lipogenesis $(5,6)$. In normal conditions lipogenesis takes place mainly in the liver and adipose tissue. The liver is a very important organ for systemic energy homeostasis - regulating glucose and lipid metabolism. Hepatic lipogenesis, including triglyceride and cholesterol synthesis, is upregulated by high glucose influx and may be one of the reasons for the development of NAFLD. The pathogenesis of NAFLD could be explained by the double-hit" hypothesis $(7,8)$. The first hit" is associated with lipid metabolism disorders in the liver (an increased uptake and concentration of fatty acids from intensified lipogenesis and disturbed process of $\beta$-oxidation of fatty acids in the mitochondria) which translates to the accumulation of lipids in hepatocytes, mainly triglycerides $(9,10)$. High concentrations of fatty acids in hepatocytes increase the expression of cytochrome P-450 2E1 (CYP 2E1), an enzyme involved in the lipids peroxidation, which leads to the formation of reactive oxygen species in the liver (11). The second-hit" is associated with increasing oxidative stress in hepatocytes which results in inflammatory process and a further progression of the disease towards non-alcoholic steatohepatitis (NASH) (12). In the development of disease other factors are involved, such as mitochondrial dysfunction, endoplasmic reticulum stress, genetic predisposition and insulin resistance $(13,14)$.

Current therapy mainly focuses on slowing the progression and improving the metabolic disorders

Corresponding Author: Jarosław Dudka, Department of Toxicology, Medical University of Lublin, Jaczewskiego 8b, PL 20-090 Lublin, Poland. E-mail: jaroslaw.dudka@umlub.pl 
which play a significant role in the pathogenesis of NAFLD (15-17). One group of substances with a potential use in the treatment of NAFLD are polyphenols belonging to a very large group of plant-derived compounds (18). A promising candidate is the natural polyphenol - resveratrol (trans-3,4',5 trihydroxystilbene), present in several plants (grapes or berries) as well as in products, such as red wine. Resveratrol leads to a decrease in expression as well as activity of SREBP-1c - major transcription factor for de novo lipogenesis (19). Resveratrol also decreases the availability of fatty acids (decreased acetyl-CoA carboxylase activity), and consequently the synthesis of triglycerides (20). Under normal physiological conditions, the liver mitochondria are able to handle and maintain a balanced level of fatty acids by $\beta$-oxidation. However, disturbed and inadequate $\beta$-oxidation is observed in NAFLD due to the increased fatty acids concentrations in the liver (21). Recent studies showed that resveratrol may increase fatty acids $\beta$-oxidation by stimulating mitochondrial biogenesis and increased autophagy in cells through the cAMP-PRKA-AMPK-SIRT1 signaling pathway (22).

In vitro studies of de novo lipogenesis may be useful in the investigation of biochemical mechanisms leading to the accumulation of fat in the liver and the role of diet in this process. These models are also important tools in testing new therapeutic strategies for the treatment of NAFLD and drug resistance in hepatocellular carcinoma. In order to study the mechanisms involved in the process of hepatic steatosis, HepG2 cells line (human hepatocellular carcinoma) is often used $(23,24)$. Consequently, the aim of this study was to evaluate the effect of resveratrol on the de novo lipogenesis and mitochondrial activity in HepG2 cells treated with high glucose concentrations.

\section{MATERIALS AND METHODS}

\section{Chemicals}

The following substances were used in the study: glucose (Sigma-Aldrich, Steinheim, Germany), resveratrol (Sigma-Aldrich, Steinheim, Germany), MTT (Thiazolyl blue tetrazolium bromide, SigmaAldrich, Steinheim, Germany), DMSO (dimethyl sulfoxide, Avantor Performance Materials Poland S.A., Gliwice, Poland), PBS (phosphate buffered saline, Biomed Serum and Vaccine Production Plant Ltd, Lublin, Poland). In this study, Eagle's Minimal Essential Medium (EMEM, ATTC, Manassas, USA) was used. Fetal Bovine Serum (FBS), antibiotics solutions: penicillin, streptomycin, amphotericin $\mathrm{B}$ and trypsin solution (Trypsin $0.25 \%$ / EDTA $0.02 \%$ in PBS w/o Ca, Mg with Phenol red) were supplied by PAN-Biotech GmbH, Aidenbach, Germany.

\section{Cell culture}

The research was performed on the HepG2 cell line (Hepatocellular carcinoma, human, ATTCNumber: HB-8065, American Type Culture Collection, Manassas, USA). The HepG2 cell line was grown in Eagle's Minimal Essential Medium (EMEM) containing normal glucose concentration $(5 \mathrm{mmol} / \mathrm{L})$ supplemented with a $10 \%$ heatinactivated FBS, $100 \mathrm{U} / \mathrm{ml}$ penicillin, $100 \mu \mathrm{g} / \mathrm{ml}$ streptomycin and $2.5 \mu \mathrm{g} / \mathrm{ml}$ amphotericin B. HepG2 cells were cultured in a monolayer of approx. $80 \%$ confluency in a $\mathrm{CO}_{2}$ cell incubator at $37^{\circ} \mathrm{C}$ in an atmosphere of $5 \% \mathrm{CO}_{2}$. After multiplication, the cells were tripsinized from the bottom of the culture flask. Cell suspension was later added to the EMEM medium and used for further investigation. The suspension of HepG2 cells was prepared at a density of $1 \times 10^{6}$ cells $/ \mathrm{ml}$ and then transferred to 24-well cell culture plates (SPL Lifescience, Gyeonggi-do, Korea) to carry out the staining (by Nile Red; MitoTracker Green FM and Hoechst 33342) and to 96-well cell culture plates (SPL Lifescience, Gyeonggi-do, Korea) to assess the viability of cells treated with glucose and resveratrol. These plates were incubated for 24 hours in order to achieve cell adhesion.

\section{Experimental procedure}

The stock solution of resveratrol at a concentration of $1 \mathrm{mM}$ was prepared by dissolving it in DMSO and then, diluted in the EMEM medium to the concentrations used in the work, ie. 10 and $20 \mu \mathrm{M}$. The final concentration of DMSO did not exceed $0.1 \%$.

Tested HepG2 cells groups used in the study were incubated with glucose and resveratrol in final concentration as follows,

- the control group (normal glucose concentrations $-5.5 \mathrm{mM}$ ), without tested substance;

- glucose $25 \mathrm{mM}$

- glucose $33 \mathrm{mM}$

- resveratrol $10 \mu \mathrm{M}$

- resveratrol $20 \mu \mathrm{M}$

- glucose $25 \mathrm{mM}$ together with resveratrol (10 or $20 \mu \mathrm{M})$

- glucose $33 \mathrm{mM}$ together with resveratrol $(10$ or $20 \mu \mathrm{M})$

The working solutions were prepared ex tempore in the EMEM medium. The solutions of test substances were added to the cells and incubated 
24 hours. After incubation, HepG2 cells were subjected to morphological evaluation.

\section{Assessment of lipid accumulation in HepG2 cells by Nile Red staining}

In order to visualize steatosis of HepG2 cells, Nile Red stain (Nile Red Bioreagent suitable for fluorescence, Sigma-Aldrich, Steinheim, Germany) was used. Nile Red (9-diethylamino$5 \mathrm{H}$-benzo $[\alpha]$ phenoxazine-5-one) is a fluorescent, lipophilic dye that is applied as a vital stain for the detection of intracellular lipid droplets. Nile Red is characterized by two specific spectra of fluorescence: yellow-gold fluorescence (excitation 450-500 nm, emission > $528 \mathrm{~nm}$ ) and red fluorescence (excitation $515-560 \mathrm{~nm}$, emission > $590 \mathrm{~nm})(25,26)$. The stock solution of Nile Red $(0.5 \mathrm{mg} / \mathrm{ml})$ was prepared in acetone (Acetone, Avantor Performance Materials, Gliwice, Poland) and stored at $4^{\circ} \mathrm{C}$, protected from light. The solution of Nile Red $(5 \mu \mathrm{g} / \mathrm{ml})$, used for the staining of the intracellular lipids, was prepared ex tempore by diluting stock solution of dye (1:100) in phosphate-buffered saline (PBS). After 24 hours incubation with the test substances, HepG2 cells were washed three times with PBS. Cells were stained with Nile Red solution in the dark for 5 minutes at room temperature. Afterwards, the cells were washed again three times with PBS. The HepG2 cells steatosis was visualized using fluorescence microscopy (Nikon Eclipse Ti, Japan). The intensity of fluorescence was assessed as: mild (a few scattered lipid vacuoles within examined slide $-<50 \%$ ), moderate (more vacuoles visible equally dispersed within examined slide $-\approx$ $50 \%$ ) and severe (the slide covered by numerous lipid vacuoles $->50 \%$ ). Each experiment was conducted in three independent repetitions $(\mathrm{n}=3)$ and representative photographs were presented.

\section{Evaluation of mitochondrial activity in HepG2 cells by MitoTracker Green FM staining} MitoTracker Green FM dye (2-[3-[5,6-dichloro1,3-bis[[4-(chloromethyl)phenyl]methyl]-1,3dihydro-2H-benzimidazol-2-ylidene]-1-

propenyl]-3-methyl-, chloride, M7514, ThermoFisher Scientific, USA) passively penetrates through the cell membrane and accumulates in active mitochondria, resulting in green fluorescence. This fluorescent dye specifically stain mitochondria independently of the mitochondrial membrane potential (27). After 24 hours incubation with the test substances, HepG2 cells were washed three times with PBS. HepG2 cells were incubated with staining agent at $37^{\circ} \mathrm{C}$ for 10 minutes. After incubation, cells were washed three times with the PBS solution and observed under the Nikon Eclipse Ti microscope. Each experiment was conducted in three independent repetitions $(\mathrm{n}=3)$ and representative photographs were selected.

\section{Nucleic acid staining by Hoechst 33342}

Hoechst 33342 nucleic acid dye (Hoechst 33342, Trihydrochloride, Trihydrate, H1399, ThermoFisher Scientific, Oregon, USA) is a cellpermeant nuclear counterstain that emits blue fluorescence when bound to dsDNA. The stock solution of Hoechst dye $(10 \mathrm{mg} / \mathrm{mL}, 16.23 \mathrm{mM})$ was prepared by dissolving the contents of one vial $(100 \mathrm{mg})$ in $10 \mathrm{~mL}$ of deionized water and stored at $4^{\circ} \mathrm{C}$, protected from light. The Hoechst staining solution was prepared ex tempore by diluting the Hoechst stock solution 1:2.000 in PBS. After 24 hours incubation with the test substances, HepG2 cells were washed three times with PBS. The cells were incubated with staining solution for 10 minutes, protected from light. After incubation, cells were washed three times with the PBS solution and observed under the Nikon Eclipse Ti microscope. Each experiment was conducted in three independent repetitions $(\mathrm{n}=3)$ and representative photographs were chosen.

\section{The locations of used dyes (Nile Red, MitoTracker Green FM and Hoechst 33342) in HepG2 cells}

The stains localization in HepG2 cells was determined finally with images taken in three color channels superimposed by NIS-Elements, Microscope Imaging Software (Nikon Instruments). These three staining agents were used together to differentiate from the background noise (fluorescence of membrane phospholipids) from actual vacuoles' lipids (steatosis).

\section{Cell viability assay}

To assess cell viability, MTT test based on the cleavage of the yellow tetrazolium salt MTT to purple formazan crystals by metabolic active cells was used. MTT Assay (DB-ALM Protocol n ${ }^{\circ} 17$, ECVAM - European Centre for the Validation of Alternative Methods, Database Service on Alternative Methods to Animal Experimentation) was performed. The formazan concentration is measured spectrophotometrically. To assess the impact on cell viability, glucose and resveratrol were added to the HepG2 cells in the same volume $(100 \mu \mathrm{l} /$ well) and incubated for 24 hours. After incubation, $10 \mu \mathrm{l}$ of MTT solution $(5 \mathrm{mg} / \mathrm{ml})$ was added to each well and incubated for 3 hours at $37^{\circ} \mathrm{C}$. At the end of incubation, the culture medium was carefully removed from each well, and $100 \mu \mathrm{l}$ 
DMSO were added (at room temperature). The cell culture plates were placed on a shaker for 5 minutes. The absorbance of each well was measured at $550 \mathrm{~nm}$ and $620 \mathrm{~nm}$ as a reference wavelength using the automated absorbance microplate reader $\mathrm{EL}_{\mathrm{x}} 808_{\mathrm{IU}}$ (Bio-Tek Instruments Inc.). The viability of treated HepG2 cells was expressed as \% of the negative control (HepG2 cells without test substances - normal glucose concentrations $5.5 \mathrm{mM}$ ). Each experiment was completely repeated five times. Three wells of each formulation were loaded on five different plates. Thus, the results are expressed as the mean of fifteen $(n=15)$ measurements of each formulation. Bars represent standard deviation.

\section{Morphology examination of HepG2 cells}

The morphology of HepG2 cells were assessed using Nikon Eclipse Ti microscope. Semiquantitative analysis was conducted using a fourlevel rating scale: 0 - normal; "+" low morphological changes; "++" - moderated changes; " $+++"$ - frequent changes. Each experiment was repeated five times $(n=5)$ and each result was the average of the observations obtained.

\section{STATISTICAL ANALYSIS}

The results of MTT assay were expressed as mean \pm SD. Experimental data were analysed with the aid of the GraphPad Prism software (version 5.01 for Windows; GraphPad Software Inc., San Diego, CA, USA). The statistical significance among the groups was determined using the analysis of variance (ANOVA) with Tukey's post-hoc test. Differences between groups were considered significant at $p<0.05$.

\section{RESULTS}

Morphology examination of HepG2 cells after co-treatment with high glucose concentrations and resveratrol

Based on the morphology examination, there was no significant change in the degree of adhesion of HepG2 cells to the plate in each of the experimental groups. However, an increase in the number of vacuoles in the cytoplasm have been reported in groups of cells exposed to high glucose concentrations (Figure 1, Table1).
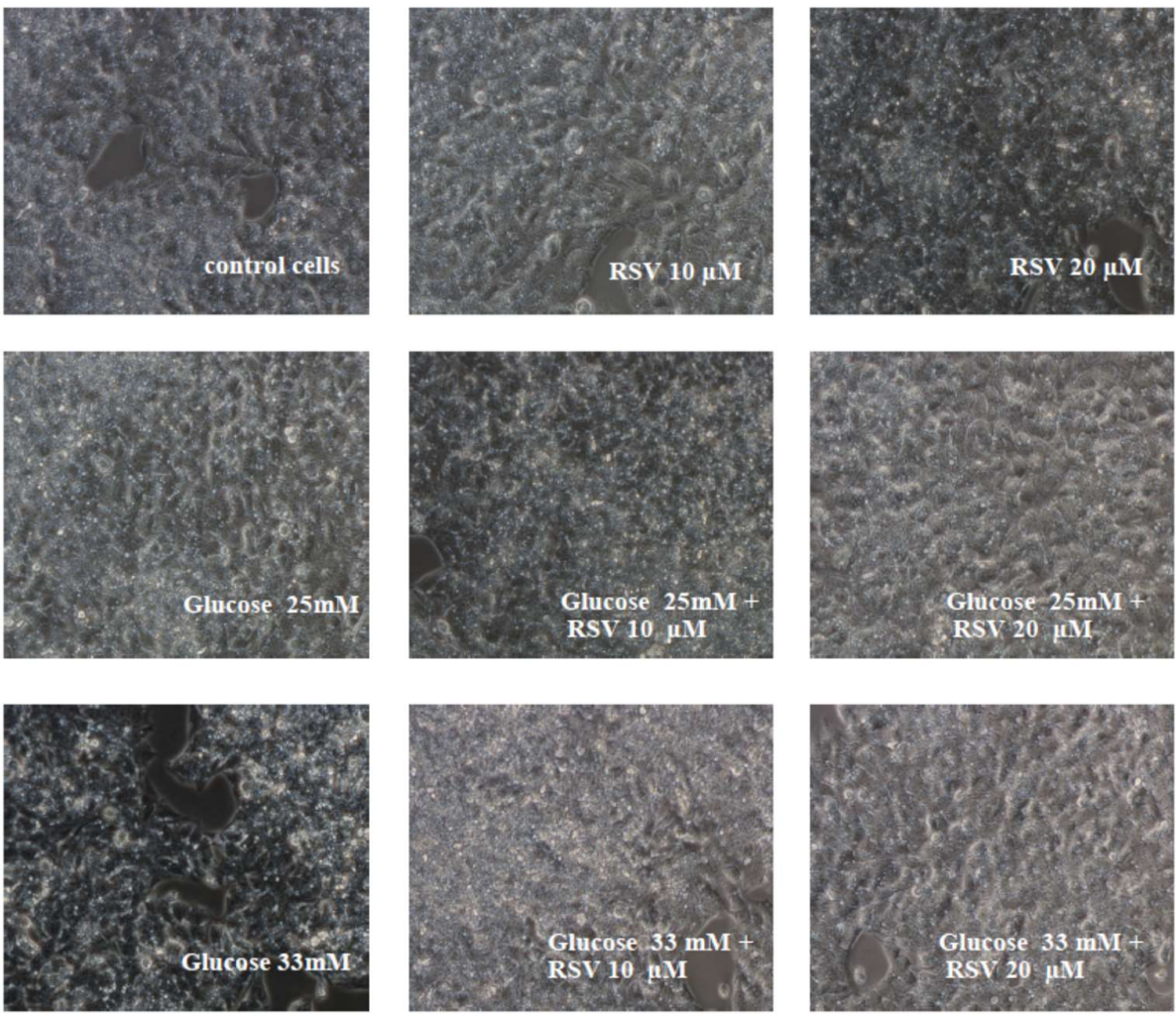

Figure 1. Morphology changes in HepG2 cells after co-treatment with high glucose concentrations and resveratrol (magnification x 100). Control group - HepG2 cells cells without tested substances (normal glucose concentration - 5.5 $\mathrm{mM}), \mathrm{RSV}$ - resveratrol. The procedure was repeated five times $(\mathrm{n}=5)$ and representative photographs were chosen. 
Table 1. Evaluation of morphology changes in HepG2 cells after co-treatment with high glucose concentrations and resveratrol.

\begin{tabular}{|c|c|c|c|c|}
\hline Experimental groups & $\begin{array}{l}\text { Adhesion } \\
\text { to the plate }\end{array}$ & $\begin{array}{l}\text { Granules in the } \\
\text { cytoplasm }\end{array}$ & $\begin{array}{l}\text { Changed shape of } \\
\text { the nucleus } / 100^{*}\end{array}$ & $\begin{array}{c}\text { Changed size of the } \\
\text { nucleus/100* }\end{array}$ \\
\hline Control group & +++ & ++ & 8 & 11 \\
\hline RSV $10 \mu \mathrm{M}$ & +++ & ++ & 10 & 14 \\
\hline RSV $20 \mu \mathrm{M}$ & +++ & ++ & 16 & 18 \\
\hline Glucose $25 \mathrm{mM}$ & +++ & +++ & 9 & 13 \\
\hline Glucose $33 \mathrm{mM}$ & +++ & +++ & 18 & 21 \\
\hline $\begin{array}{l}\text { Glucose } 25 \mathrm{mM} \\
\text { and RSV } 10 \mu \mathrm{M}\end{array}$ & +++ & +++ & 15 & 17 \\
\hline $\begin{array}{l}\text { Glucose } 25 \mathrm{mM} \\
\text { and RSV } 20 \mu \mathrm{M}\end{array}$ & +++ & +++ & 20 & 24 \\
\hline $\begin{array}{l}\text { Glucose } 33 \mathrm{mM} \\
\text { and RSV } 10 \mu \mathrm{M}\end{array}$ & +++ & +++ & 22 & 29 \\
\hline $\begin{array}{l}\text { Glucose } 33 \mathrm{mM} \\
\text { and RSV } 20 \mu \mathrm{M}\end{array}$ & +++ & +++ & 46 & 52 \\
\hline \multicolumn{5}{|c|}{$\begin{array}{l}+<50 \% \text { of cells } ;++\approx 50 \% \text { of cells; }+++>50 \% \text { of cells. Semi-quantitative results are the average from five } \\
\text { observations }(\mathrm{n}=5) \text { for each group. Control group }- \text { HepG2 cells without tested substances (normal glucose } \\
\text { concentration }-5.5 \mathrm{mM}), \mathrm{RSV}-\text { resveratrol } * \text { based on morphological evaluation after Hoechst } 33342 \text { staining (Fig. } \\
\text { 4). These results come from three independent tests }(\mathrm{n}=3 \text { ) for each group. }\end{array}$} \\
\hline
\end{tabular}

The effect of resveratrol on lipid accumulation in HepG2 cells treated with high glucose concentrations (Nile Red staining)

A microscopic evaluation of HepG2 cells after exposure to high glucose concentrations (25 or 33 $\mathrm{mM}$ ) showed that the cytoplasm of these cells contains numerous different sized fluorescent bodies corresponding to lipid accumulation, mainly classified as microvacuolar steatosis (small, discrete vacuoles). The fluorescence intensity in cells was severe. In the cytoplasm of control cells (untreated) the presence of microvacuolar an inherent steatosis and moderate fluorescence was also observed. There was no significant effect of $10 \mu \mathrm{M}$ resveratrol on the number of lipids vacuoles in HepG2 cells exposed to high glucose concentrations ( 25 or $33 \mathrm{mM}$ ). In the group of cells treated with $20 \mu \mathrm{M}$ resveratrol and $25 \mathrm{mM}$ glucose the increased background fluorescence was observed. The co-administration of $20 \mu \mathrm{M}$ resveratrol with high glucose concentration reduced the steatosis compared with cells treated with glucose alone (Figures 2, 5 and Table 2). The fluorescence intensity in these cells was moderate.

The effect of resveratrol on mitochondrial activity in HepG2 cells treated with high glucose concentrations (MitoTracker Green FM staining)

Resveratrol at a dose of $20 \mu \mathrm{M}$ increased the mitochondrial activity of HepG2 cells treated with high glucose concentrations (25 and $33 \mathrm{mM}$ ) compared with cells treated only with glucose or resveratrol and compared with the control group.
High glucose concentrations ( 25 or $33 \mathrm{mM}$ ) did not result in increased mitochondrial activity in HepG2 cells as compared to the control group (Figure 3 ).

The effect of resveratrol on dsDNA in HepG2 cells treated with high glucose concentrations (Hoechst 33342 staining)

In HepG2 cells exposed on $33 \mathrm{mM}$ glucose and 20 $\mu \mathrm{M}$ resveratrol significant increase in the number of deformed cell nucleus with changed shape and size was observed (nearly $50 \%$ of cells) compared with cells treated only with glucose or resveratrol and compared with the control group (Figure 4, Table 1).

The locations of used dyes (Nile Red, MitoTracker Green FM and Hoechst 33342) in HepG2 cells

In order to better interpret the results and reduce background fluorescence (fluorescence of membrane phospholipids) observed in HepG2 cells after Nile red staining, the locations of used dyes (Nile Red, MitoTracker Green FM and Hoechst 33342) in cells were assessed with images taken in three colour channels, superimposed by NISElements, Microscope Imaging Software (Nikon Instruments) (Figure 5).

The effect of resveratrol on the viability of HepG2 cells treated with high glucose concentrations (MTT test)

10 and $20 \mu \mathrm{M}$ Resveratrol did not affect the viability of HepG2 cells treated with 25 or $33 \mathrm{mM}$ glucose (Figure 6). 

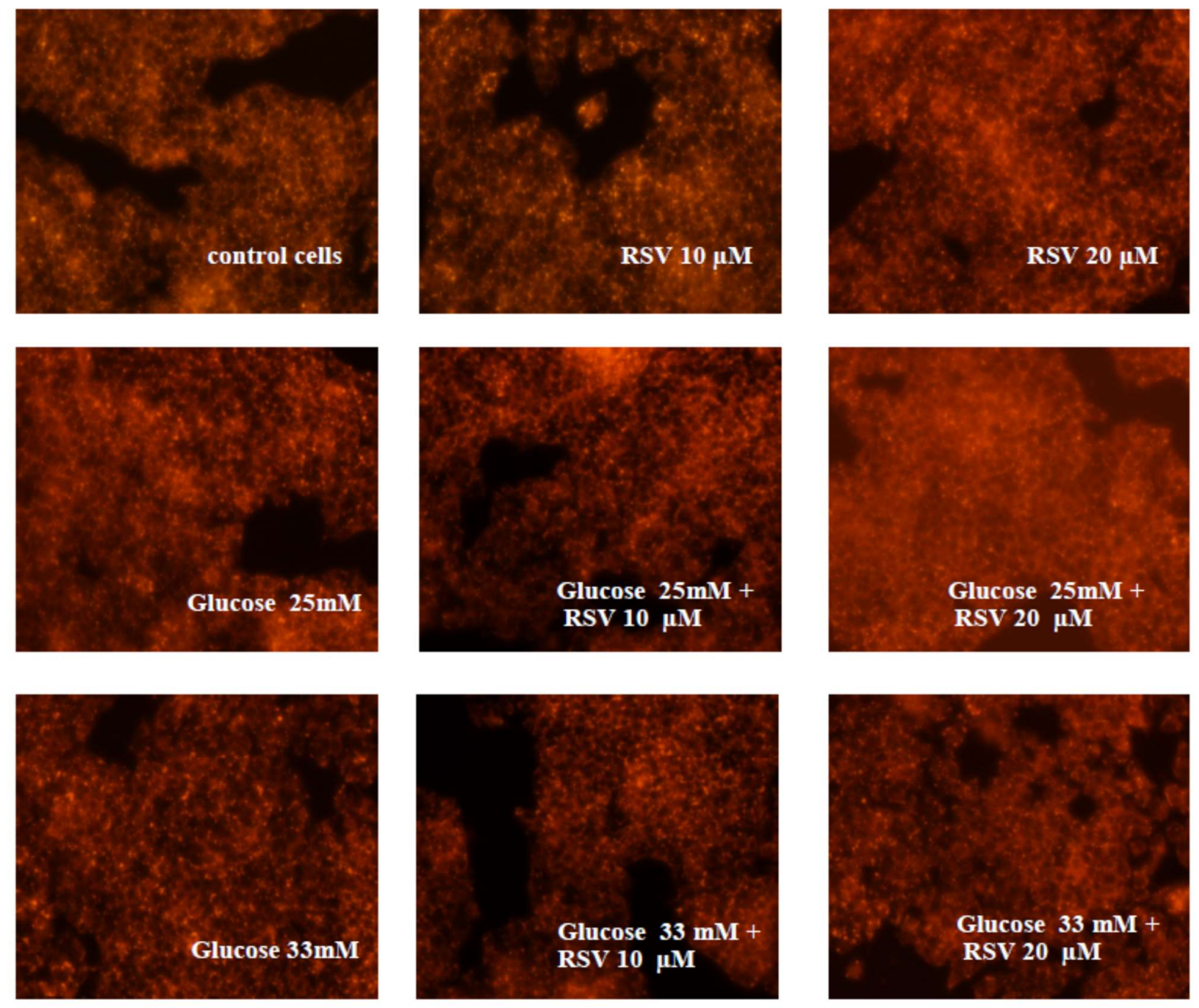

Figure 2. Fluorescence of intracellular lipids by Nile Red staining. Effect of resveratrol on lipid accumulation in HepG2 cells treated with high glucose concentrations for $24 \mathrm{~h}$ (magnification x 100). Lipid vacuoles in cells showed a yellowgold fluorescence. Control group - HepG2 cells without tested substances (normal glucose concentration - $5.5 \mathrm{mM}$ ), RSV - resveratrol. The procedure was repeated three times $(n=3)$ and representative photographs were chosen.

Table 2. The features of steatosis and the intensity of Nile Red fluorescence in the HepG2 cells

\begin{tabular}{lll}
\hline Experimental groups & $\begin{array}{l}\text { microvacuolar } \\
\text { steatosis }\end{array}$ & $\begin{array}{l}\text { intensity } \\
\text { of fluorescence }\end{array}$ \\
\hline Control group & $+/++$ & $+/++$ \\
RSV $10 \mu \mathrm{M}$ & $+/++$ & $+/++$ \\
RSV 20 $\mu \mathrm{M}$ & $+/++$ & $+/++$ \\
Glucose $25 \mathrm{mM}$ & +++ & +++ \\
Glucose 33mM & +++ & +++ \\
Glucose 25mM and RSV $10 \mu \mathrm{M}$ & +++ & $++/+++$ \\
Glucose 25mM and RSV 20 $\mu \mathrm{M}$ & ++ & ++ \\
Glucose 33mM and RSV $10 \mu \mathrm{M}$ & +++ & $++/++$ \\
Glucose 33mM and RSV $20 \mu \mathrm{M}$ & ++ & ++ \\
\hline
\end{tabular}

Micro-vacuolar steatosis: $+<50 \%$ of cells, $++\approx 50 \%$ of cells, $+++>50 \%$ of cells. Intensity of fluorescence: + mild, ++ moderate, +++ severe. Control group - HepG2 cells without tested substances (normal glucose concentration $5.5 \mathrm{mM}), \mathrm{RSV}-\mathrm{HepG} 2$ cells treated with resveratrol. Semi-quantitative results are the average from three observations $(\mathrm{n}=3)$. 
The evaluation of the viability of cells in experimental groups with resveratrol was carried out in the presence of its solvent (DMSO). For the purpose of this study, an additional group of HepG2 cells was prepared incubated with a $0.1 \%$ solution of DMSO. In the MTT assay, there were no significant differences between the viability of the control group and the cells treated with the solvent (viability of cells incubated with a $0.1 \%$ of DMSO - 98.8\% \pm 3.9 ).

\section{DISCUSSION}

De novo lipogenesis, which is caused by the increased consumption of monosaccharides (glucose and fructose) is responsible for development of many different metabolic diseases such as obesity, type 2 diabetes, metabolic syndrome and non-alcoholic fatty liver disease (NAFLD). Lipogenesis is the metabolic pathway that synthesizes endogenous fatty acids from excess monosaccharides (28). Lipogenesis takes place under positive energy balance conditions, mainly in adipose tissue but also in the liver. Fatty acids can be next metabolized into triglycerides for energy storage (1). The pathogenesis of NAFLD is closely associated with metabolic disorders which can be observed as increase in fatty acids concentration in the liver and, at the same time, the $\beta$-oxidation processes are disrupted which leads to the increased triglycerides accumulation in the cytoplasm of hepatocytes, which are later stored in the form of lipid vacuoles. NAFLD usually takes the form of simple steatosis (in the microscopic image mainly microvacuolar steatosis of cytoplasm is observed) but in approx. $15 \%$ of cases can evolve into fatty liver disease aggravated by inflammations (non-alcoholic steatohepatitis NASH) (9).
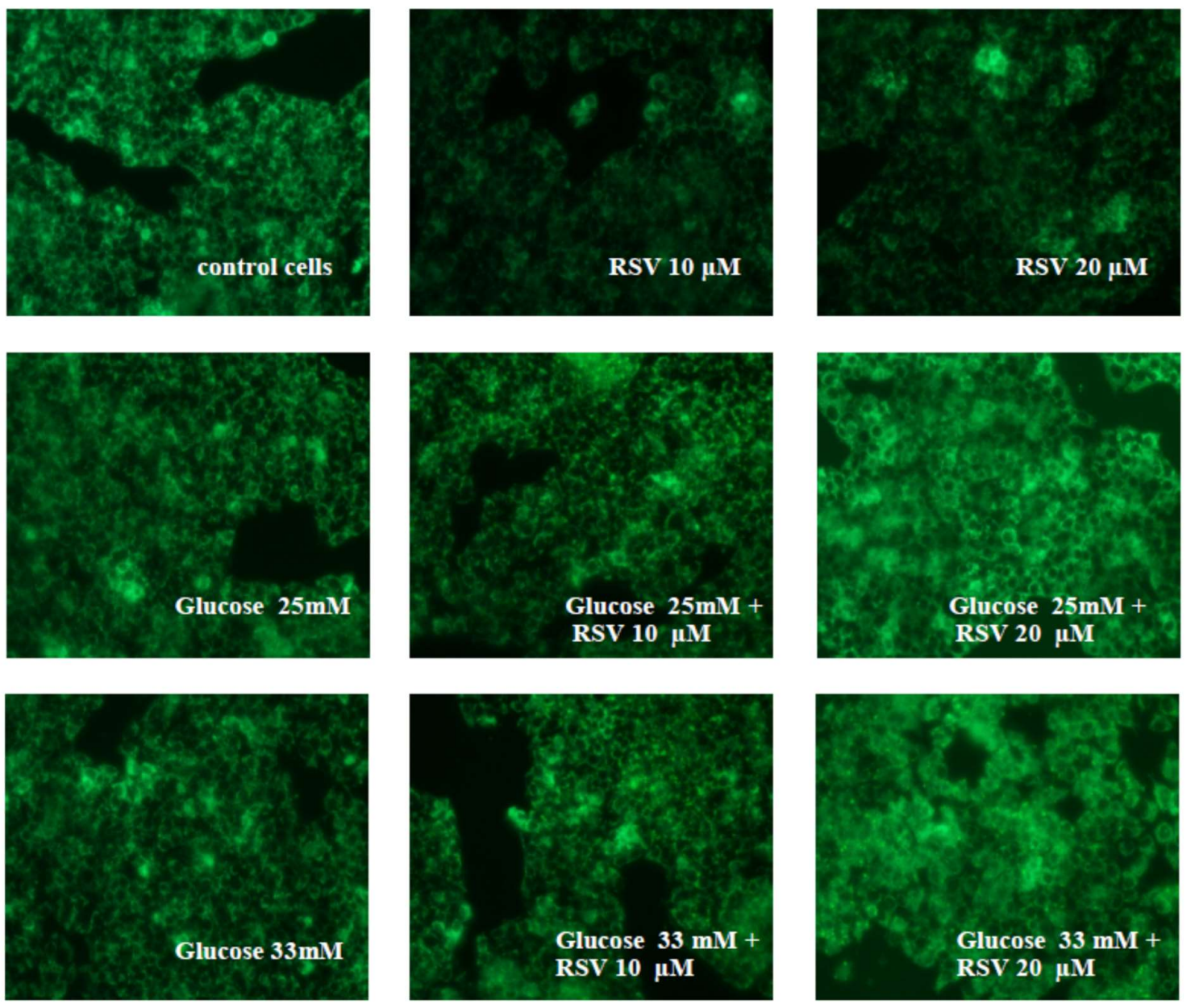

Figure 3. Fluorescence of active mitochondria by MitoTracker Green FM staining. Effect of resveratrol on mitochondrial activity in HepG2 cells treated with high glucose concentrations for $24 \mathrm{~h}$ (magnification x 100). Control group - HepG2 cells without tested substances (normal glucose concentration - $5.5 \mathrm{mM}$ ), RSV - resveratrol. The procedure was repeated three times $(n=3)$ and representative photographs were chosen. 
Although the risk factors of NAFLD have been identified, little is still known about the most efficient therapeutic strategy for treatment (17). Focus on this, lipogenesis pathway may be the key to cure various diseases dependent on intensified lipogenesis, such as NAFLD, obesity or cancers. Therefore, we decided to investigate the effect of resveratrol on de novo lipogenesis and mitochondrial activity of HepG2 cells exposed to high glucose concentrations (25 or $33 \mathrm{mM})$. The upper reference limit of blood glucose level in people is $5.5 \mathrm{mM}$, when it reaches the level of 10 $\mathrm{mM}(180 \mathrm{mg} \%)$ the glucose passes to the urine. However, in this model to induce steatosis in $24 \mathrm{~h}$ higher level of glucose were used (25 and $33 \mathrm{mM}$ ). These glucose concentrations were used to induce de novo lipogenesis and steatosis of cells in in vitro models (29-31). The study revealed that high glucose concentrations (25 or $33 \mathrm{mM}$ ) induced steatosis in HepG2 cells (cytoplasm of these cells contains numerous fluorescent bodies corresponding to lipid accumulation, classified as microvacuolar steatosis - small lipid droplets) (Figures 2, 5). Steatosis of HepG2 cells was visualized by Nile red staining. Nile red (9diethylamino-5H-benzo[ $\alpha]$ phenoxazine-5-one) is a fluorescent, lipophilic vital dye that is applied for detection of intracellular lipid droplets, usually triglycerides. Greenspan et al. demonstrated the utility of Nile red as a stain to detect lipid droplets by fluorescence microscopy but this dye can also interact and exhibit fluorescence in the presence of phospholipid, cholesterol and cholesteryl esters (26). Because, especially in the group of cells treated with $25 \mathrm{mM}$ glucose and $20 \mu \mathrm{M}$ resveratrol, increased background fluorescence after Nile red staining was observed (Figure 2), we decided to take images in three different color channels (for Nile Red, MitoTracker Green FM, and Hoechst 33342) superimposed by NIS- Elements, Nikon Microscope Imaging Software. These three dyes (staining colours) were used to differentiate the background noise (fluorescence of mitochondrial membrane phospholipids from stimulated mitochondria) from actual vacuoles' lipids (Figure 5).
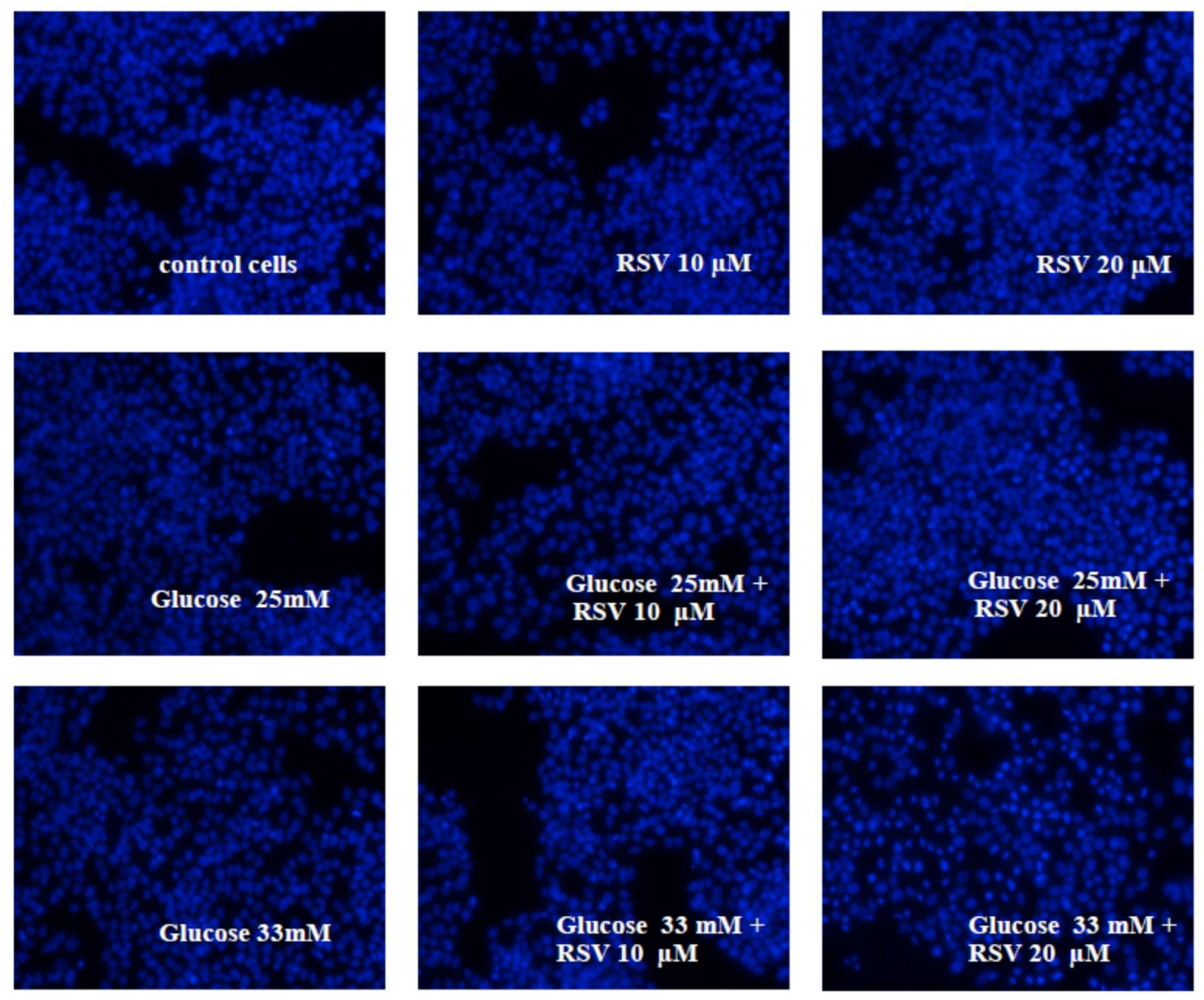

Figure 4. Fluorescence of dsDNA by Hoechst 33342 staining (magnification x 100). Control group - HepG2 cells without tested substances (normal glucose concentration - $5.5 \mathrm{mM}$ ), RSV - resveratrol. The procedure was repeated three times $(\mathrm{n}=3)$ and representative photographs were chosen. 

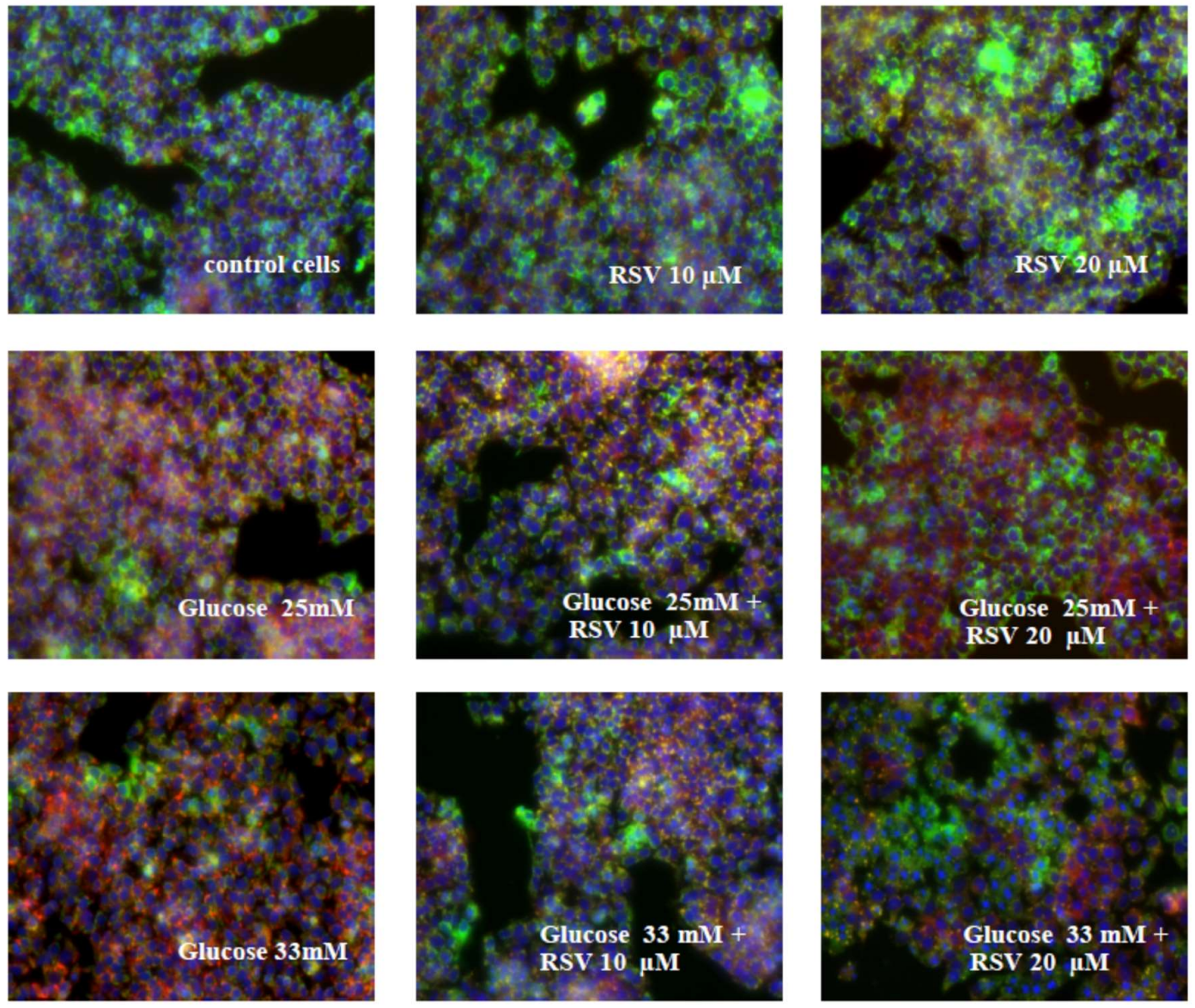

Figure 5. The dyes (Nile Red, MitoTracker Green FM and Hoechst 33342) localization in HepG2 cells cells determined with images taken in three colour channels superimposed by NIS-Elements, Microscope Imaging Software (Nikon Instruments) (magnification x 100). Control group - HepG2 cells without tested substances (normal glucose concentration - $5.5 \mathrm{mM})$, RSV - resveratrol. The procedure was repeated three times $(\mathrm{n}=3)$ and representative photographs were chosen.

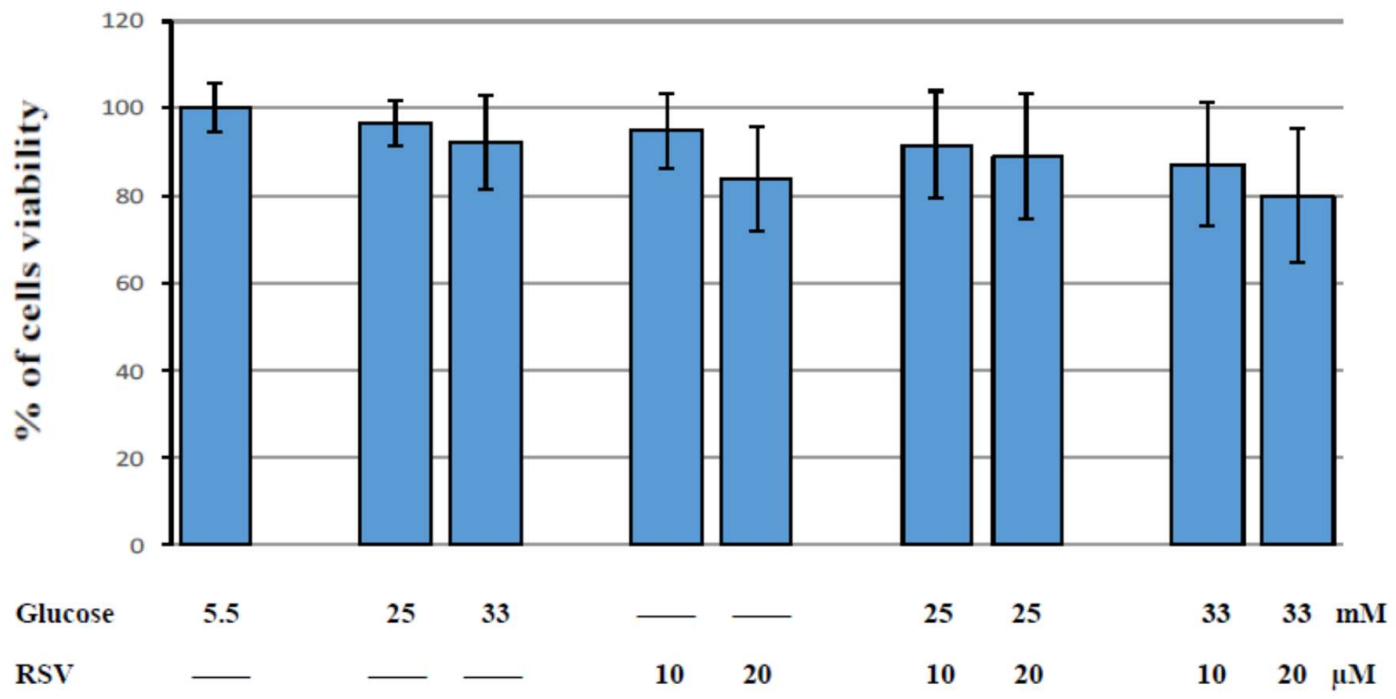

Figure 6. Effects of resveratrol (RSV) on the viability of HepG2 cells treated for $24 \mathrm{~h}$ with high glucose concentrations in the MTT test. Data presented as percentage of control \pm SD. There was no statistical difference among the means vs control. Each experiment was completely repeated five times. Three wells of each formulation were loaded on five different plates. Thus, the results are expressed as the mean of fifteen $(n=15)$ measurements of each formulation. Bars represent standard deviation. 
Normally, de novo lipogenesis is responsible for the synthesis of about $5 \%$ of hepatic fat content, however, in case of NAFLD, de novo synthesis is elevated and responds to $25 \%$ of the hepatic fat content (1). This process is regulated and intensified by glucose and insulin. Glucose and insulin stimulate transcription factors carbohydrate response element binding protein (ChREBP) and sterol regulatory element binding protein 1c (SREBP-1c) that promotes transcription of all genes involved in lipogenesis, such as peroxisome proliferator-activated receptor (PPAR) (28). Resveratrol used in this study is a polyphenol with strong and favorable effect on lipid metabolism of the body.

Resveratrol, in vitro, in concentration of 8.7 $\mu \mathrm{M}$ and $7.8 \mu \mathrm{M}$ has shown $50 \%$ inhibition of microsomal liver metabolism of ibrutininib, respectively in rats and human (32). Moreover, Sergides et al. have shown that following oral administration of a single dose of Evelor $500 \mathrm{mg}$ tablets (containing trans-resveratrol) mean total concentration in plasma of 15 healthy volunteers of free resveratrol, resveratrol glucuronides and sulphate is equal to $5.67 \mu \mathrm{g} / \mathrm{ml}$, that corresponds to $248 \mu \mathrm{M}(33)$. Thus we assumed that 10 and $20 \mu \mathrm{M}$ are suitable for this study.

Previously published studies demonstrated that RSV decreased expression as well as activity of ChREBP and SREBP-1c - the most important transcription factor for de novo lipogenesis (18). Our study showed that resveratrol in higher dose $(20 \mu \mathrm{M})$ reduced the steatosis of HepG2 cells treated with high glucose concentration (Figure 5, Table 2). These results are in accordance with the studies published by Shang et al. where HepG2 cells cells were also exposed to high glucose concentrations to get the effect of cell steatosis (30). These studies showed that resveratrol reduced triglyceride accumulation by activating AMPactivated protein kinase (AMPK).

Microvacuolar steatosis observed in NAFLD is also associated with fatty acids $\beta$-oxidation disorders in mitochondria. Microvacuolar steatosis observed in HepG2 cells in the current study may result from the disturbance in the mitochondrial electron transport chain. The disturbance in mitochondrial electron transport chain leads to an excess of NADH which inhibits beta-oxidation of free fatty acids. Therefore, we decided to evaluate the effect of resveratrol on mitochondrial activity in HepG2 cells exposed to high glucose concentrations. Resveratrol at a higher dose $(20 \mu \mathrm{M})$ increased the mitochondrial activity of HepG2 cells treated with high glucose concentrations (25 and $33 \mathrm{mM}$ ). This beneficial effect is most likely responsible for the decrease in steatosis of HepG2 cells.

Our earlier studies showed that resveratrol decreased steatosis in HepG2 cells induced by fatty acids mixtures and reduced the mitochondrial oxidative stress in cells. We also observed the favorable effect of resveratrol on the mitochondrial membrane potential in HepG2 cells treated with the mixtures of fatty acids (34).

In this study, we also decided to evaluate the effect of resveratrol on the viability of HepG2 cells incubated with high glucose concentrations using the MTT assay. Resveratrol exhibits an antitumor activity depending on the dose $(35,36)$. Stervbo et al. noted that the half-maximal inhibitory concentration - $\mathrm{IC}_{50}$ for resveratrol was $60 \mu \mathrm{M}$, after 24 hours incubation with HepG2 cells. Therefore, in this study the lower doses of resveratrol were used, i.e. 10 and $20 \mu \mathrm{M}$, which we assumed would not significantly reduce the viability of hepatocellular carcinoma cells, as it was confirmed in our study in the MTT assay. These concentrations of resveratrol, used in our study, are effective in in vitro studies on cellular models of NAFLD (18). Resveratrol did not affect the viability of HepG2 cells treated with glucose.

Unfortunately in HepG2 cells treated with 20 $\mu \mathrm{M}$ resveratrol and $33 \mathrm{mM}$ glucose significant increase in the number of deformed cell nucleus with changed shape and size (nearly $50 \%$ of cells) was observed (Figure 4, Table 1). The cells that are undergoing apoptosis exhibit nuclear condensation and DNA fragmentation, which can be detected by staining with Hoechst 33342 and fluorescence microscopy.

\section{CONCLUSIONS}

The results obtained in this study indicate that resveratrol at higher dose limited the steatosis of HepG2 cells induced by high glucose concentrations and increased the mitochondrial activity of cells. This beneficial effect seems to be promising and could prove helpful in the treatment of NAFLD. Therapeutic targeting of lipogenesis pathway may be a good option for treatment of this disease. These results should be continued in further studies in order to confirm both the effectiveness of this polyphenol (the influence on transcription factors for de novo lipogenesis) and safety of resveratrol (the impact of cell apoptosis). 


\section{ACKNOWLEDGMENT AND FUNDING}

Financial support for this study was provided by the Medical University of Lublin, Poland [grant number DS 38].

\section{DECLARATIONS}

The authors report no conflicts of interest. This article is approved by all co-authors. The authors alone are responsible for the content and writing of this article.

\section{REFERENCES}

1. Ameer F, Scandiuzzi L, Hasnain S, Kalbacher H, Zaidi N. De novo lipogenesis in health and disease. Metabolism, 2014; 63:895-902. doi: 10.1016/j.metabol.2014.04.003.

2. Bellentani S. The epidemiology of non-alcoholic fatty liver disease. Liver Int, 2017; 37 Suppl 1:8184. doi: 10.1111/liv.13299.

3. Masarone M, Federico A, Abenavoli L, Loguercio C, Persico M. Non-alcoholic fatty liver. Epidemiology and natural history. Rev Recent Clin Trials, 2014; 9:126-133.

4. Vernon G, , Baranova A, Younossi ZM. Systematic review: the epidemiology and natural history of non-alcoholic fatty liver disease and non-alcoholic steatohepatitis in adults. Aliment Pharmacol Ther, 2011; 34:274-285. doi: 10.1111/j.13652036.2011.04724.x.

5. Moore JB, Gunn PJ, Fielding BA. The role of dietary sugars and de novo lipogenesis in nonalcoholic fatty liver disease. Nutrients, 2014; 6:5679-5703. doi: 10.3390/nu6125679.

6. Papandreou D, Andreou E. Role of diet on nonalcoholic fatty liver disease: An updated narrative review. World J Hepatol, 2015;57:5575-582. doi: 10.4254/wjh.v7.i3.575.

7. Andersen N, Borlak J. Molecular mechanisms and therapeutic targets in steatosis and steatohepatitis. Pharmacol Rev 2008; 60:311-357.

8. Day CP. Pathogenesis of steatohepatitis. Best Pract Res Clin Gastroenterol, 2002; 16:663-678.

9. Berlanga A, Guiu-Jurado E, Porras JA, Auguet T. Molecular pathways in non-alcoholic fatty liver disease. Clin Exp Gastroenterol, 2014; 7:221-239. doi: 10.2147/CEG.S62831.

10. Byrne CD, Olufadi R, Bruce KD, Cagampang FR, Ahmed MH. Metabolic disturbances in nonalcoholic fatty liver disease. Clin Sci (Lond), 2009; 116(7):539-564. doi: 10.1042/CS20080253.

11. Prompila N, Wittayalertpanya S, Komolmit P. Hepatic cytochrome P450 2E1 activity in nonalcoholic fatty liver disease. J Med Assoc Thai, 2008; 91:733-773.

12. Takaki A, Kawai D, Yamamoto K. Multiple hits, including oxidative stress, as pathogenesis and treatment target in Non-Alcoholic Steatohepatitis
(NASH). Int J Mol Sci, 2013; 14: 20704-20728. doi: $10.3390 /$ ijms 141020704 .

13. Byrne CD, Targher G. NAFLD: a multisystem disease. J Hepatol, 2015; 62 (1 Suppl):S:47-64. doi: 10.1016/j.jhep.2014.12.012

14. Tilg H, Moschen AR. Evolution of inflammation in nonalcoholic fatty liver disease: the multiple parallel hits hypothesis. Hepatology, 2010; 52:1836-1846. doi: 10.1002/hep.24001.

15. Abd El-Kader SM, El-Den Ashmawy EM. Nonalcoholic fatty liver disease: The diagnosis and management. World J Hepatol, 2015; 7:846-858. doi: 10.4254/wjh.v7.i6.846.

16. Martín-Domínguez V, González-Casas R, Mendoza-Jiménez-Ridruejo J, García-Buey L, Moreno-Otero R. Pathogenesis, diagnosis and treatment of non-alcoholic fatty liver disease. Rev Esp Enferm Dig, 2013; 105:409-420.

17. Hardy T, Anstee QM, Day CP. Nonalcoholic fatty liver disease: new treatments. Curr Opin Gastroenterol, 2015; 31:175-183. doi: 10.1097/MOG.0000000000000175.

18. Aguirre L, Portillo MP, Hijona E, Bujanda L. Effects of resveratrol and other polyphenols in hepatic steatosis. World J Gastroenterol 2014; 20:7366-7380. doi: 10.3748/wjg.v20.i23.7366.

19. Kohjima M, Higuchi N, Kato M, Kotoh K, Yoshimoto T, Fujino, T. et al. SREBP-1c, regulated by the insulin and AMPK signaling pathways, plays a role in nonalcoholic fatty liver disease. Int J Mol Med, 2008; 21:507-511.

20. Gnoni GV, Paglialonga G. Resveratrol inhibits fatty acid and triacylglycerol synthesis in rat hepatocytes. Eur J Clin Invest, 2009; 39:211-218. doi: $10.1111 /$ j. $1365-2362.2008 .02077 . x$.

21. Morris EM, Scott R, Thyfault JP, Ibdahl JA. Mitochondria and redox signaling in steatohepatitis. Antioxid Redox Signal, 2011; 15:485-504. doi: 10.1089/ars.2010.3795.

22. Zhang Y, Chen ML, Zhou Y, Yi L, Gao YX, Ran $\mathrm{L}$, et al. Resveratrol improves hepatic steatosis by inducing autophagy through the cAMP signaling pathway. Mol Nutr Food Res, 2015; 59:1443-1457. doi: 10.1002/mnfr.201500016.

23. Chavez-Tapia NC, Rosso N, Tiribelli C. In vitro models for the study of non-alcoholic fatty liver disease. Curr Med Chem, 2011;18:1079-1084.

24. Gómez-Lechón MJ, Donato MT, Martínez-Romero A, Jiménez N, Castell JV, O'Connor JE. A human hepatocellular in vitro model to investigate steatosis. Chem Biol Interact, 2007; 165:106-116. DOI: 10.1016/j.cbi.2006.11.004.

25. Diaz G, Melis M, Batetta B, Angius F, Falchi AM. Hydrophobic characterization of intracellular lipids in situ by Nile red red/yellow emission ratio. Micron, 2008; 39:819-824. doi: 10.1016/j.micron.2008.01.001.

26. Greenspan P, Mayer EP, Fowler SD. Nile red: a selective fluorescent stain for intracellular lipid droplets. J Cell Biol, 1985; 100:965-973.

27. Pendergrass W, Wolf N, Poot M. Efficacy of MitoTracker Green and CMXrosamine to measure 
changes in mitochondrial membrane potentials in living cells and tissues. Cytometry A, 2004; 61:162-169. DOI: 10.1002/cyto.a.20033.

28. Sanders FW, Griffin JL. De novo lipogenesis in the liver in health and disease: more than just a shunting yard for glucose. Biol Res, 2016; 91:452468. doi: 10.1111/brv.12178.

29. Gorgani-Firuzjaee S, Meshkani R. SH2 domaincontaining inositol 5-phosphatase (SHIP2) inhibition ameliorates high glucose-induced denovo lipogenesis and VLDL production through regulating AMPK/mTOR/SREBP1 pathway and ROS production in HepG2 cells. Free Radic Biol Med, 2015; 89:679-689. doi: 10.1016/j.freeradbiomed.2015.10.036.

30. Shang J, Chen LL, Xiao FX, Sun H, Ding HC, Xiao H. Resveratrol improves non-alcoholic fatty liver disease by activating AMP-activated protein kinase. Acta Pharmacol Sin, 2008;29:698-706. doi: 10.1111/j.1745-7254.2008.00807.x.

31. Zhang Y, Takemori H, Wang C, Fu J, Xu M, Xiong L, Li N, Wen X. Role of salt inducible kinase 1 in high glucose-induced lipid accumulation in HepG2 cells and metformin intervention. Life Sci, 2017; 173:107-115. doi: 10.1016/j.lfs.2017.02.001.

32. Wen J, Bao SS, Zhang BW, Liu TH, Ou-Yang QG, Cai JP, Zhou HY. Inhibitory Effect of Resveratrol on the Pharmacokinetic of Ibrutinib by UPLCMS/MS. Drug Dev Ind Pharm. 2018; 29:1-16. doi: 10.1080/03639045.2018.1514044.

33. Sergides C, Chirilă M, Silvestro L, Pitta D, Pittas A. Bioavailability and safety study of resveratrol $500 \mathrm{mg}$ tablets in healthy male and female volunteers. Exp Ther Med. 2016 Jan;11(1):164170 .

34. Izdebska M, Piątkowska-Chmiel I, Korolczuk A, Herbet M, Gawrońska-Grzywacz M, Gieroba R, Sysa M, Czajkowska-Bania K, Cygal M, Korga A, Dudka J. The beneficial effects of resveratrol on the steatosis and mitochondrial oxidative stress in HepG2 cells. Can J Physiol Pharmacol, 2017; 95:1442-1453. doi: 10.1139/cjpp-2016-0561.

35. Stervbo U, Vang O, Bonnesen C. Time- and concentration dependent effects of resveratrol in HL-60 and HepG2 cells. Cell Prolif, 2006; 39:479493. DOI: $10.1111 / \mathrm{j} .1365-2184.2006 .00406 . x$

36. Tameda M, Sugimoto K, Shiraki K, Inagaki Y, Ogura S, Kasai C, Yoneda M, Okamoto R, Yamamoto N, Takei Y, Ito $M$, Nobori $T$. Resveratrol sensitizes HepG2 cells to TRAILinduced apoptosis. Anticancer Drugs, 2014; 25:1028-1034. doi: 10.1097/CAD. 0000000000000128 . 